\title{
Prostatic cancer and chronic respiratory and renal disease in British cadmium workers: a case control study
}

\author{
B G ARMSTRONG* AND G KAZANTZIS
}

From the TUC Centenary Institute of Occupational Health, London School of Hygiene and Tropical
Medicine, London WC1E 7HT, UK

ABSTRACT Deaths due to prostatic cancer, renal cancer, bronchitis or emphysema, and nephritis or nephrosis in three cohorts of cadmium workers have been investigated in a case-control study. Evidence of an association of risk for these diseases with intensity and duration of exposure to cadmium was sought. The only clearly statistically significant finding was of an association of deaths coded as bronchitis or emphysema with "high" levels of exposure to cadmium fume, which was related also to duration of exposure. There was suggestive evidence also $(p \bumpeq 0 \cdot 10)$ of an increased risk for nephritis or nephrosis after high exposure. Marginally increased risks were observed for prostatic cancer after high or "medium" exposure, but these were not statistically significant.

The mortality of a cohort of 6995 male workers exposed to cadmium has been previously reported.' A limitation of that study, in common with most other cohort studies, is that its large scale precluded the detailed assessment of exposure experienced by each member of the cohort. Associations between exposure and disease may thus have been obscured through misclassification into exposure groups that were necessarily rather crude.

The completion of tracing of the study population allowed a more detailed assessment of workers' exposures, which was also economical. This was accomplished by selecting the deaths from the diseases of interest, with appropriately matched controls (referents) from within the study population, and going to some lengths to assess the exposures to cadmium and other toxic agents in the subjects of this much reduced group.

This method of selecting case-control sets from within a cohort is known to strengthen the validity of the case-control approach ${ }^{2}$ and is becoming increasingly popular in occupational epidemiology. ${ }^{3}$

\footnotetext{
${ }^{*}$ Present address: School of Occupational Health, 1130 Pine Avenue West, McGill University, Montreal, Canada.

Received 10 September 1984 Accepted 19 November 1984
}

\section{Methods}

In addition to the cohort reported on earlier, ${ }^{1}$ referred to here as $\mathrm{C} 1$, cases were taken from two furthere cohorts, that of nickel-cadmium battery workers reported by Sorahan, ${ }^{45}$ referred to as $\mathrm{C} 2$, and that of copper-cadmium alloy workers reported by Holden, ${ }^{6}$ referred to as C3.

Diagnostic categories were taken from the 8th revision of the International Classification of Diseases (ICD). These comprised cancer of the prostate (ICD 185), cancer of the kidney (ICD 189.0), "bronchitis and emphysema" (ICD 490-492), and "nephritis and nephrosis" (ICD 580-584). Use of the latter two terms does not signify the coexistence of bronchitis and emphysema or of nephritis and nephrosis but indicates only the diagnostic groupings used in this study.

Deaths were included from among men born before 1940 with at least one year's employment before 1970 from the three cohorts of cadmium workers, C1, C2, and C3.

Deaths in $\mathrm{C} 1$ were multi-cause coded, and use was made of this to include cases of nephritis and nephrosis from $\mathrm{C} 1$ men who had died with this disease mentioned on the death certificate but not coded as underlying cause. There were no such "other mentions" of renal cancer, and only one of prostatic cancer, in the "always low" exposure 
group. Other mentions of this disease, and of bronchitis or emphysema were not included in the study.

Sixteen deaths were initially coded as due to "acute cadmium poisoning." Nevertheless, there was sufficient information on the death certificate and elsewhere to reclassify 13 of these as in fact due to chronic respiratory disease, and one as due to chronic renal disease. These were included as cases of bronchitis and emphysema or nephritis and nephrosis respectively.

Up to three controls for each case were sampled from the cohorts from which the cases arose as follows:

(1) From the same plant as the case.

(2) From among those alive and in the study at the age when the case died.

(3) Matched as closely as possible to the date of birth of the case.

Thus referents were matched exactly by plant and age and as nearly as possible by date of birth.

Work history information on cases and controls was checked and further supplemented by examining personnel and other available records, except in a few plants in which all useful information had already been abstracted. Smoking histories were also sought and biological monitoring data collected. This work was carried out blind with respect to whether individuals were cases or controls.

Assessments of exposure on a three point scale ("high," "medium," or "low") had been made for job categories for the original cohort analysis. Additional job categories were defined as a result of new information collected for the case-control study. Assessments of exposure for these new categories were made on the same basis as those made for the cohort analysis, and previous assessments of exposure were revised if new information suggested this.

Job exposure assessments were used with work histories to compute estimates of exposure for each year of a man's working life. From these the follow- ing indices of exposure were computed for each man:

(a) Maximum exposure (ever high, ever medium, always low).

(b) Years of high exposure.

(c) Years of medium exposure.

(d) Years of low exposure.

(e) Cumulative exposure $=(25 \times$ years of high exposure $)+(5 \times$ years of medium exposure $)+(1$ $\times$ years of low exposure).

In addition, the main type of exposure to cadmium (fume, oxide dust, sulphide dust, soaps, sludge) was recorded for each man. A control subject's exposure index was computed on the basis of his work history until he achieved the age at which the case to which he was matched died.

Statistical analysis has been performed by conditional logistic regression for matched case-control sets. ${ }^{7}$ This method allows investigation of continuous risk factors (such as years of exposure) as well as estimating the risk in groups (such as ever high, ever medium, always low). For groups, odds ratios (ORs) were estimated by this method which may in practice be interpreted as risk pertaining to one group relative to another ( 1 indicating no risk; greater than 1 indicating an increased risk). For continuous variables, logistic regression coefficients were estimated from which risk following from a given level of a variable may be predicted. Estimated regression coefficients are presented here and may be interpreted as the risk predicted from ten years of exposure, 1 again indicating no risk. Likelihood ratio tests of significance of the null hyposthesis of relative risk being 1 were carried out, giving two sided $p$ values, and confidence intervals (CIs) computed on the assumption that estimates were normal on the logistic scale. Confidence intervals which do not include 1 indicate that the relative risk is significant at the $5 \%$ level.

For bronchitis and emphysema, where numbers

Table 1 Number of cases

\begin{tabular}{|c|c|c|c|c|c|c|}
\hline & \multicolumn{3}{|l|}{$C 1$} & \multirow[t]{2}{*}{$C 2$} & \multirow[t]{2}{*}{ C3 } & \multirow[t]{2}{*}{ Total } \\
\hline & $C 1.1$ & $C 1.2$ & $A l l$ & & & \\
\hline \multirow{4}{*}{$\begin{array}{l}\text { Prostatic cancer (underlying cause only) } \\
\text { Renal cancer (underlying cause only) } \\
\text { Bronchitis and emphysema } \\
\text { (underlying cause only) } \\
\text { Nephritis and nephrosis } \\
\text { (underlying cause only) } \\
\text { Nephritis and nephrosis } \\
\text { (including all mentions) }\end{array}$} & $\begin{array}{r}18 \\
5\end{array}$ & $\begin{array}{l}6 \\
1\end{array}$ & $\begin{array}{r}24 \\
6\end{array}$ & $\begin{array}{l}5 \\
1\end{array}$ & $\begin{array}{r}10 \\
2\end{array}$ & $\begin{array}{r}39 \\
9\end{array}$ \\
\hline & 109 & 53 & 162 & 36 & 78 & 276 \\
\hline & 8 & 2 & 10 & 6 & 7 & 23 \\
\hline & 16 & 5 & 21 & 6 & 7 & 34 \\
\hline
\end{tabular}

C1.1 = Lead-zinc-cadmium smelter.

C1.2 = Smaller plants (including alloys, pigments, stabilisers).

C2 $=$ Nickel cadmium battery plant.

C3 $=$ Copper cadmium alloy plant. 
Table 2 Cases and controls by exposure group

\begin{tabular}{|c|c|c|c|c|c|c|c|c|}
\hline \multirow[t]{2}{*}{ Cause } & \multicolumn{2}{|c|}{ Always low } & \multicolumn{2}{|c|}{ Ever medium } & \multicolumn{2}{|c|}{ Ever high } & \multicolumn{2}{|l|}{ Total } \\
\hline & Cases & Controls & Cases & Controls & Cases & Controls & Cases & Controls \\
\hline $\begin{array}{l}\text { Prostatic cancer } \\
\text { Renal cancer } \\
\text { Bronchitis and emphysema } \\
\text { Nephritis and nephrosis }\end{array}$ & $\begin{array}{r}24 \\
6 \\
163\end{array}$ & $\begin{array}{r}75 \\
12 \\
526\end{array}$ & $\begin{array}{r}11 \\
2 \\
64\end{array}$ & $\begin{array}{r}28 \\
10 \\
196\end{array}$ & $\begin{array}{r}4 \\
1 \\
49\end{array}$ & $\begin{array}{r}12 \\
5 \\
97\end{array}$ & $\begin{array}{r}39 \\
9 \\
276\end{array}$ & $\begin{array}{r}115 \\
27 \\
819\end{array}$ \\
\hline $\begin{array}{l}\text { (underlying cause only) } \\
\text { Nephritis and nephrosis }\end{array}$ & 12 & 42 & 5 & 19 & 6 & 8 & 23 & 69 \\
\hline (including all mentions) & 19 & 64 & 9 & 30 & 6 & 8 & 34 & 102 \\
\hline
\end{tabular}

Table 3 Risk of ever medium and ever high exposure relative to always low exposure

\begin{tabular}{llll}
\hline Cause & $\begin{array}{l}\text { ICD } \\
(8 \text { th } \text { Rev })\end{array}$ & $\begin{array}{l}\text { Ever medium/always low } \\
\text { OR }(95 \% \text { CI })\end{array}$ & $\begin{array}{l}\text { Ever high/always low } \\
\text { OR }(95 \% \text { CI })\end{array}$ \\
\hline $\begin{array}{l}\text { Prostatic cancer } \\
\text { Renal cancer }\end{array}$ & 185 & $1 \cdot 55(0.49-4.93)$ & $1.35(0 \cdot 31-5 \cdot 91)$ \\
$\begin{array}{l}\text { Bronchitis and emphysema } \\
\text { Nephritis and nephrosis }\end{array}$ & $189 \cdot 0$ & $0 \cdot 43(0.07-2 \cdot 49)$ & $0(0-10+)$ \\
$\begin{array}{l}\text { (underlying cause only) } \\
\text { Nephritis and nephrosis } \\
\text { (including all mentions) }\end{array}$ & $490-492$ & $1 \cdot 17(0.77-1 \cdot 77)$ & $1 \cdot 80(1 \cdot 12-2 \cdot 89)$ \\
\hline
\end{tabular}

are sufficient, results are given separately for the nickel cadmium battery plant (C2), the copper cadmium alloy plant (C3), and a large smelter in $\mathrm{C} 1$ (C1.1). Other plants in $\mathrm{C} 1(\mathrm{C} 1.2)$ were too small to enable interpretation of results by individual plant.

\section{Results}

Table 1 shows the number of cases for each selected disease group in relation to plant. The mean year of birth of the cases was 1906 and the mean year of death 1967. Matching ensured that the distribution of dates of birth in the controls was practically identical to that in the cases. The mean absolute difference between date of birth in controls and their respective cases was four months, confirming that matching on this variable was adequate.

All workers (including cases and controls) are subject to "healthy worker" selection effects. It is widely agreed, however, that these effects will be strongest nearer the time that a worker is known to be sufficiently fit to work-in our study the time of entry to the cohort. Since cases and controls could not be matched by time of entry to the cohort due to small numbers in some plants, this potentially con-

Table 4 Risk by years of exposure

\begin{tabular}{|c|c|c|c|}
\hline \multirow[t]{2}{*}{ Cause } & \multicolumn{3}{|c|}{ Regression coefficient ( $95 \%$ CI) } \\
\hline & Risk/ten years of low & Risk/ten years of medium & Risk/ten years of high \\
\hline $\begin{array}{l}\text { Prostatic cancer } \\
\text { Renal cancer } \\
\text { Bronchitis and emphysema } \\
\text { Nephritis and nephrosis } \\
\text { (underlying cause only) } \\
\text { Nephritis and nephrosis } \\
\text { (including all mentions) }\end{array}$ & $\begin{array}{l}1.09(0.78-1.51) \\
0.97(0.86-1.10) \\
0.95(0.56-1.60) \\
0.98(0.66-1.46)\end{array}$ & $\begin{array}{l}0.98(0.54-1.80) \\
\text { (Numbers too small) } \\
0.88(0.66-1.17) \\
0.68(0.18-2.54) \\
0.61(0.19-1.90)\end{array}$ & $\begin{array}{l}1.13(0.62-2.05) \\
1.30(1.03-1.64) \\
2.00(0.69-5.84) \\
1.97(0.69-5.61)\end{array}$ \\
\hline
\end{tabular}

founding factor was accounted for in the logistic regression analysis. All cause SMRs by year of entry to study computed from the cohort rose from 76 in the first five years to 84 in the next five years and 95 subsequently, suggesting that selection effects diminished rapidly after the first five years. Formally estimating risk of death at $0-4$ and 5-9 years from entry to study relative to 10 years or more among allo cases and controls showed a significantly reduced risk (OR $0 \cdot 36,95 \% \mathrm{CI} 0 \cdot 14-1 \cdot 00)$ for $0-5$ years, but not for 5-10 years (OR $0.90,95 \%$ CI $0.45-$ $1 \cdot 80)$. In subsequent logistic regression analyses reduced risk for the first $0-5$ years in the study is accounted for.

Table 2 gives the number of cases and controls in each exposure category. Table 3 shows the estimated risks of ever high and ever medium exposure relative to always low exposure, with $95 \%$ confidence intervals. Only the risk of bronchitis and emphysema in the ever high group is statistically significant beyond the $5 \%$ level $(p \simeq 0 \cdot 01)$. The risk of nephritis and nephrosis in the ever high group approached statistical significance $(p \bumpeq 0.10)$ when all mentions of these diseases were taken into account. Estimated risks of prostatic cancer were 
Table 5 Bronchitis and emphysema: risk by plant

\begin{tabular}{lll}
\hline Plant & OR $(95 \%$ CI & \\
\cline { 2 - 3 } & Ever medium/always low & Ever highlalways low \\
\hline C1.1 & $1.08(0 \cdot 57-2 \cdot 06)$ & $2.63(1.04-6.62)$ \\
C1.2 & $2.48(0.69-8 \cdot 99)$ & $0 \cdot 82(0.33-2.05)$ \\
C3 & $1.34(0.52-3 \cdot 49)$ & $2 \cdot 24(1.05-4 \cdot 79)$ \\
\hline
\end{tabular}

above 1, but far from statistically significant.

Years of exposure at high, medium, and low levels were considered as continuous risk factors. Table 4 shows the estimated coefficients of these variables (representing estimated risk due to ten years at the appropriate level). Again only years of high exposure for bronchitis and emphysema is clearly significant $(p \bumpeq 0.005)$. For years of high exposure and nephritis and nephrosis the risk approached statistical significance $(p \bumpeq 0 \cdot 10)$ whether mentions other than underlying cause were included or not. Cumulative exposure, as defined in the previous section, was also only clearly significant for bronchitis and emphysema $(p \bumpeq 0.001)$.

The larger number of cases of bronchitis and emphysema enabled more detailed analyses to be carried out for this disease. Risks by exposure in each of the larger component plants of the study are given in table 5 . The overall risk for ever high exposure is not apparent in plant $\mathrm{C} 2$, the nickelcadmium battery plant.

Table 6 shows the estimates of risk according to whether medium or high exposure was in the form of dust (cadmium oxide or sulphide or both) or fume. Risk due to exposure at the high level appears to be restricted to men exposed to fume. What evidence there is of risk due to medium exposure appears in both men exposed to dust and fume, but this evidence is not strong for either group.

Biological monitoring data were available for only seven of the cases and 16 controls, making formal analysis of these data impossible. It may be worth noting, however, that the one case included under nephritis and nephrosis in the ever high category from C3 had consistently high urinary cadmium concentrations (18-440 $\mu \mathrm{g} / \mathrm{l})$. Three of the remaining six cases with biological monitoring data were certified as death due to "cadmium poisoning," but on the basis of information on the death certificate these were reclassified under bronchitis and emphysema. All of these showed evidence of high cadmium absorption from urinary cadmium concentrations and two had repeated positive tests for proteinuria. The remaining three cases were also classified under bronchitis and emphysema. Only one of these had been monitored for absorption and showed high levels of cadmium in the urine.

It was possible to obtain smoking histories for fewer than $\mathbf{3 0}$ of the cases and controls, so that formal analysis of these data was also impossible.

Occupation previous to working in a cadmium plant was ascertained for most men. No consistent pattern of a relation between this past occupation and disease category was apparent. In particular, employment as a coal miner (27 men) was not a significant risk factor of bronchitis and emphysema.

Table 7 shows SMRs for the combined cohorts $\mathrm{C} 1, \mathrm{C} 2$, and $\mathrm{C} 3$ for the disease groups of present interest. These refer only to years at risk between ages 15 and 84 , so that the numbers of deaths in this table are a little fewer than the numbers of cases in the case-control study. The classification of exposure used for these SMRs is that made for the cohort as a whole, which is more subject to misclassification than that used for the case-control analysis. SMRs estimate risk relative to the general population whereas risks estimates from the case-control study are relative to men in the study with low exposure. Consideration of both indices together can aid interpretation.

The SMR's show a similar picture to the risks estimated from the case-control study. A slight trend across exposure groups is apparent for prostatic cancer, with no SMR approaching statistical significance. A stronger trend is present for nephritis and nephrosis but again no SMR is statistically significant. For bronchitis and emphysema, the SMR for the ever high group is clearly significant $(p<$

Table 6 Bronchitis and emphysema: risk by type of exposure

\begin{tabular}{lll}
\hline Type of exposure & OR $(95 \%$ CI $)$ & \\
\cline { 2 - 3 } & Ever medium/always low & Ever high/always low \\
\hline Dust & $1.45(0.68-3 \cdot 11)$ & $0.93(0.39-2 \cdot 21)$ \\
Fume & $1.15(0.73-1.81)$ & $2 \cdot 43(1.40-4 \cdot 20)$ \\
\hline
\end{tabular}


Table 7 SMRs: cohorts C1, C2, C3 combined

\begin{tabular}{|c|c|c|c|c|c|c|c|c|c|}
\hline \multirow[t]{2}{*}{ Disease } & \multirow[t]{2}{*}{$I C D(8 t h)$} & \multicolumn{2}{|c|}{ Always low } & \multicolumn{2}{|c|}{ Ever medium } & \multicolumn{2}{|l|}{ Ever high } & \multicolumn{2}{|l|}{ Total } \\
\hline & & Obs/Exp & SMR $(95 \% \mathrm{CI})$ & $\overline{O b s / E x p}$ & $\overline{S M R}(95 \% \mathrm{CI})$ & $\overline{O b s / E x p}$ & $S M R(95 \% C I)$ & $\overline{O b s / E x p}$ & SMR $195 \%$ \\
\hline $\begin{array}{l}\text { Prostatic cancer } \\
\text { Bronchitis and emphysema } \\
\text { Nephritis and nephrosis }\end{array}$ & $\begin{array}{l}185 \\
490-492 \\
580-584\end{array}$ & $\begin{array}{c}24 / 22 \cdot 1 \\
146 / 119 \cdot 9 \\
11 / 14 \cdot 9\end{array}$ & $\begin{array}{l}109(70-161) \\
122(102-142) \\
74(37-132)\end{array}$ & $\begin{array}{c}9 / 6 \cdot 8 \\
64 / 48 \cdot 8 \\
7 / 5 \cdot 1\end{array}$ & $\begin{array}{l}132(61-251) \\
131(99-163) \\
137(55-283)\end{array}$ & $\begin{array}{c}4 / 2 \cdot 6 \\
37 / 21 \cdot 1 \\
4 / 2 \cdot 2\end{array}$ & $\begin{array}{l}154(42-394) \\
175(119-232) \\
182(50-465)\end{array}$ & $\begin{array}{c}37 / 31 \cdot 4 \\
247 / 190 \cdot 0 \\
22 / 22 \cdot 2\end{array}$ & $\begin{array}{r}118(80-15 \overline{\text {. }}) \\
130(114-146 \\
99(62-159)\end{array}$ \\
\hline
\end{tabular}

0.001), with the lower SMRs for the ever medium and always low groups significant at around the $\mathbf{P}=$ 0.05 level.

\section{Discussion}

Impaired ventilatory function has been seen in occupational groups exposed to cadmium by inhalation. $^{8}$ Recently, however, attention has shifted to the effects of cadmium on the kidney, and to its possible carcinogenic effect on prostate and lung. The results from this study show that the impact of cadmium on mortality has in these cohorts overall been more through respiratory disease than renal disease or prostatic cancer.

The case-control study confirms the exposureresponse relation of intensity and duration of exposure to cadmium with deaths due to bronchitis or emphysema which was observed in $\mathrm{C} 1 .^{1}$ The existence of these relations makes it unlikely that confounding exposures could be responsible for the excess deaths observed. The overall high/low relative risk estimated from the case-control study $(1 \cdot 80)$ was similar to the SMR for the ever high group (175), a somewhat surprising result in view of the raised SMR for the always low group. The high/ low risk estimated from study $\mathrm{C} 1(2.63)$ was lower than the SMR for the ever high group (434) but both were highly statistically significant. Of the 276 deaths included within the category bronchitis and emphysema, 21 gave emphysema as the underlying cause of death. This small number together with the variation between physicians in diagnostic practice with regard to this disease led to the grouping of emphysema with bronchitis for the purpose of this study. The estimate of risk for exposure to dust as opposed to fume (Table 6) relies heavily on the nickel cadmium battery plant (C2) which does not show any apparent risk, either by SMR or casecontrol analysis. Sorahan comes to similar conclusions with regard to the nickel cadmium battery plant. $^{5}$

Kipling and Waterhouse noted a statistically significant excess incidence of cancer of the prostate in a group of men in the nickel cadmium battery plant $\mathrm{C} 2,{ }^{9}$ although the most recent follow up of this population shows that experience since the initial observation has yielded no further evidence for a risk from cadmium. ${ }^{5}$ The $\mathrm{C} 3$ group showed an excess among vicinity (medium) workers, but not cadmium (high) workers. ${ }^{6}$ The $\mathrm{C} 1$ study showed no excess of prostatic cancers. Combining the studies' SMRs (table 7) shows that overall, whereas a slight trend in SMRs across exposure groups is apparent, no SMR is significantly different from 100 . This picture is confirmed in the case-control study (with improved exposure data), where indices including duration as well as intensity of exposure were also not statistically significant, although marginally in the direction of increased risk with increased exposure.

The small number of deaths from renal cancer must make interpretation of our negative findings for this disease cautious, ${ }^{9}$ as may be seen from the breadth of the confidence intervals of the risk estimates. We can say, however, that there was no support from this study for the evidence of a link between renal cancer and cadmium as claimed by Kolonel. ${ }^{10} \Omega$

Nephritis and nephrosis is also uncommon as the underlying cause of death in the general population so that we have only 23 cases in this diagnostic category. The large estimated high/low risk (table 6) and relation with duration of exposure (table 7) provides suggestive if not clearly significant evidence that some of the six cases classified as nephritis and nephrosis in the ever high exposure group of our study were related to past exposure to cadmium. Consideration of the SMRs, however, shows that it is partly the low risk in the always low group that leads to the large high/low risk. In one of the ever high cases exposure to cadmium was noted on the death certificate as the cause of death. If all deaths in $\mathrm{C} 1$ for which the death certificate mentions nephritis or nephrosis are included as cases a small nonsignificant risk of medium relative to low exposure is apparent in addition to the high/low (table 3), but this is not related to duration of exposure (table 4).

At the time of deciding on diseases to include in the case-control study, there was little evidence apart from the observations of Lemen et al "11 to suggest a link between exposure to cadmium and lung cancer. It was thus decided that the relatively costly exercise of including the substantial number of cases of this disease in the case-control study was not warranted. Since then, the experimental findings of Takenaka et al $^{12}$ have renewed interest in the possi- 
bility that exposure to cadmium in some form may give rise to lung cancer in man. A case-control study of deaths from lung cancer is currently in progress.

We thank the International Lead Zinc Research Organisation, New York, USA, who funded this study. We are grateful to the members of our steering committee for providing information and advice, in particular to Dr R G Adams, Mr T Sorahan, Dr H Holden, and Mr D A O'Malley for making data from cohorts C2 and C3 available to us, and not least to Ms Jacky Willett for data processing and office coordination.

Requests for reprints to: Dr G Kanzantzis, TUC Centenary Institute of Occupational Health, London School of Hygiene and Tropical Medicine, Keppel Street (Gower Street), London WC1E 7HT.

\section{References}

' Armstrong BG, Kazantzis G. The mortality of cadmium workers. Lancet 1983;i:1425-7.

${ }^{2}$ Mantel N. Synthetic retrospective studies and related topics. Biometrics 1973;29:479-86.
${ }^{3}$ Liddell FDK, McDonald JC, Thomas DC. Methods of cohort analysis: appraisal by application to asbestos mining. Journal of the Royal Statistical Society A 1977;140:469-91.

4 Sorahan T. Mortality study of nickel-cadmium battery workers. Cadmium 81. In: Proceedings of the third international cadmium conference, Miami, 1981. London: Cadmium Association, 1982:138-41.

s Sorahan T, Waterhouse JAH. Mortality of nickel-cadmium battery workers by the method of regression models in life tables. Br J Ind Med 1983;40:293-300.

- Holden H. Further mortality studies in workers exposed to cadmium fume. In: Occupational exposure to cadmium. London Cadmium Association, 1980.

' Breslow NE, Day NE. Statistical methods in cancer research. In: The analysis of case-control studies. Vol 1. Lyon: International Agency for Research on Cancer, 1980.

${ }^{8}$ Bonnell JA, Kazantzis G, King E. A follow-up study of men exposed to cadmium oxide fume. Br J Ind Med 1959;16:13547.

${ }^{9}$ Kipling MD, Waterhouse JAH. Cadmium and prostatic carcinoma. Lancet 1967; i:730-1.

${ }^{10}$ Kolonel LN. Association of cadmium with renal cancer. Cancer 1976;37: 1782-7.

"Lemen RA, Lee JS, Wagoner JK Blejer HP. Cancer mortality among cadmium production workers. Ann NY Acad Sci 1976;271:273-9.

12 Takenaka S, Oldiges H, König H, Hochrainer D, Oberdörster G. Carcinogenicity of cadmium chloride aerosols in Wistar rats. $J$ Natl Cancer Inst 1983;70:367-71. 